\title{
Staging procedures fail to benefit women with borderline ovarian tumours who want to preserve fertility: a retrospective analysis of 448 cases
}

Na Li $i^{1,2,3+}$, Jinhai Gou ${ }^{1,2+}$, Lin $\mathrm{Li}^{1,2}$, Xiu Ming ${ }^{1,2}$, Ting Wenyi Hu ${ }^{1,2}$ and Zhengyu $\mathrm{Li}^{1,2^{*}}$ (D)

\begin{abstract}
Background: To evaluate the effect of clinicopathologic factors on the prognosis and fertility outcomes of BOT patients.

Methods: We performed a retrospective analysis of BOT patients who underwent surgical procedures in West China Second University Hospital from 2008 to 2015. The DFS outcomes, potential prognostic factors and fertility outcomes were evaluated.

Results: Four hundred forty-eight patients were included; 52 recurrences were observed. Ninety-two patients undergoing FSS achieved pregnancy. No significant differences in fertility outcomes were found between the staging and unstaged surgery groups. Staging surgery was not an independent prognostic factor for DFS. Laparoscopy resulted in better prognosis than laparotomy in patients with stage I tumours and a desire for fertility preservation.

Conclusion: Patients with BOT fail to benefit from surgical staging. Laparoscopy is recommended for patients with stage I disease who desire to preserve fertility. Physicians should pay more attention to risk of recurrence in patients who want to preserve fertility.
\end{abstract}

Keywords: Borderline ovarian tumour, Surgery staging, Fertility-sparing surgery, Disease-free survival

\section{Background}

Borderline ovarian tumour (BOT) is a unique type of tumour with a better prognosis than malignant ovarian tumours. BOT usually occurs in women 10 years younger than those with epithelial ovarian cancer. The majority of the women with BOT are diagnosed in earlier

\footnotetext{
* Correspondence: zhengyuli@scu.edu.cn

${ }^{+} \mathrm{Na}$ Li and Jinhai Gou contributed equally to this work.

'Department of Gynecology and Obstetrics, West China Second University Hospital, Sichuan University, Chengdu, Sichuan 610041, P.R. China

${ }^{2}$ Key Laboratory of Obstetrics \& Gynecologic and Pediatric Diseases and Birth Defects of Ministry of Education, West China Second Hospital, Sichuan University, Chengdu, Sichuan 610041, P.R. China

Full list of author information is available at the end of the article
}

stages, reported about $75 \%$ diagnosed at stage I $[1,2]$. It was reported that in BOT specimens, the significant marker for malignant tumours, Ki67 Labeling Index value, ranged from 2 to $40 \%$ [3].

The clinical management of BOT has evolved since our understanding of its biological behaviour has increased over the latest two decades. The primary treatment for BOT is surgical removal of the tumour, while fertility-sparing surgery (FSS) is emphasized in women who desire to preserve their fertility. The role of comprehensive surgical staging in the treatment of BOT is still controversial. Due to that peritoneal implants are a significant prognostic index and the most common sites

(C) The Author(s). 2020 Open Access This article is licensed under a Creative Commons Attribution 4.0 International License, which permits use, sharing, adaptation, distribution and reproduction in any medium or format, as long as you give appropriate credit to the original author(s) and the source, provide a link to the Creative Commons licence, and indicate if changes were made. The images or other third party material in this article are included in the article's Creative Commons licence, unless indicated otherwise in a credit line to the material. If material is not included in the article's Creative Commons licence and your intended use is not permitted by statutory regulation or exceeds the permitted use, you will need to obtain permission directly from the copyright holder. To view a copy of this licence, visit http://creativecommons.org/licenses/by/4.0/ The Creative Commons Public Domain Dedication waiver (http://creativecommons.org/publicdomain/zero/1.0/) applies to the data made available in this article, unless otherwise stated in a credit line to the data. 
of implants include the omentum and peritoneal surfaces, comprehensive surgical staging including resection of the primary borderline tumour, abdominal/pelvic cytologic washings, omentectomy, and peritoneal biopsies is recommended. However, it is reported that routine lymphadenectomy is not recommended $[4,5]$. In general, comprehensive surgical staging, adequate tissue sampling, and adequate follow-up period are essential aspects for optimal clinical management of BOT [2]. It is still inconsistent of the benefits of staging surgery, while a recent systematic literature review showed that staging surgery, including hysterectomy and lymphadenectomy for BOT, is not supported based on present studies [6-8]. As the ratio of uterine or nodal metastasis is low in early-stage BOT, the risk of surgical complications and the benefits of surgical staging must be balanced carefully.

To evaluate the effect of clinicopathologic factors on the prognosis and fertility outcomes of BOT patients, this study was performed.

\section{Methods}

Clinical data of BOT patients were collected retrospectively in West China Second University Hospital between January 2008 and December 2015. Patients with a pathological diagnosis of BOT who underwent surgery were enrolled in this study. The patients with concurrent ovarian cancer, other malignant reproductive tumours, or incomplete data were excluded. This study was approved by the Medical Ethics Committee of West China Second University Hospital. Data were collected from medical records, telephone interview and out-patient review. Essential information included data of age, lesion location, International Federation of Gynecology and Obstetrics (FIGO) stage, histological subtype, surgical information, chemotherapy information, and follow-up information. Although the FIGO ovarian staging classification was revised on 1 January 2014, we used the previous staging (2009) classification guideline for consistency [9]. In addition, histological type was determined according to the World Health Organization (WHO) system (2003). Pathological specimens were evaluated by two independent pathologists experienced in gynaecologic pathology. The tumours were divided into four histological types: serous, mucinous, endometrioid, and other types. Micropapillary lesions were defined as serous tumours with complex micropapillary structures [10]. Microinvasion lesions were defined as stromal invasion limited in an area of less than $10 \mathrm{~mm}^{2}$ [10]. Surgical mentioned in this study included FSS, which was performed to conserve the uterus and at least one ovary, and radical resection, which was performed to remove the uterus and bilateral salpingo-oophoron [11]. Moreover, several surgery types need to be defined: staging, and non-staging surgery. Staging was defined as surgery including peritoneal washing and/or biopsies, pelvic and para-aortic lymphadenectomy (sampling or systematic), and omentectomy. Other surgery was defined as non-staging surgery [12]. Four types of FSSs are mentioned as follows: unilateral salpingo-oophorectomy, unilateral cystectomy, bilateral cystectomy, and unilateral salpingo-oophorectomy plus contralateral cystectomy. The latter three surgeries were defined as cystectomy. Patients were followed-up once every 3 months for the first 2 years, every 6 months for 3-5 years after the surgery, and once per year thereafter. Gynaecological examination, abdominal ultrasonography, and serum tumour marker evaluation, especially ca-125, were performed in each follow-up. Considering the favourable prognosis, disease-free survival (DFS, defined as the duration from the primary surgery to the first recurrence or the last follow-up) was applied to assess oncological outcomes, rather than over-all survival (OS).

DFS, recurrence rate, and pregnancy rate were selected as the primary outcomes in this study. All statistical analyses were performed using the Statistical Package for Social Sciences (SPSS) statistical software (version 20.0). The Student's $t$-test was used for statistical analysis of unpaired data. Univariate and multivariate Cox regression analysis were used to determine the factors affecting recurrence. A $P$-Value $<0.05$ was considered statistically significant.

\section{Results}

\section{Patient characteristics}

A total of 448 patients with BOT were enrolled in this study. The demographics and clinicopathological characteristics are shown in Table 1.

The median age at diagnosis was 37.1 years (range: 11-82 years). The majority of the patients were in FIGO stage I $(n=347,77.46 \%)$, with a few cases of stage II ( $n=20,4.46 \%)$, stage III $(n=74,16.52 \%)$, and stage IV ( $n=7,1.56 \%)$. The most common pathological type of BOT was serous $(n=258,57.59 \%)$, followed by mucinous $(n=150,33.48 \%)$, serous/mucinous $(n=32,7.14 \%)$, and endometrioid $(n=8,1.79 \%)$. Notably, most patients had unilateral lesions $(n=352,78.57 \%)$, whereas 96 (21.43\%) patients had bilateral lesions. Among the patients enrolled, 81 (18.08\%) had micropapillary lesions, 88 (19.64\%) had microinvasion lesions, and 25 (5.58\%) had carcinogenesis lesions.

Regarding surgical approach, 298 patients (66.52\%) underwent laparotomy and 150 patients (33.48\%) underwent laparoscopy; 118 patients (26.34\%) underwent staging surgery, whereas the rest underwent non-staging surgery (330 patients, 73.66\%). Abdominal/pelvic washings or ascites were collected prior to surgery for all patients, and positive involvement was identified in 27 
Table 1 Demographics of patients with borderline ovarian tumors

\begin{tabular}{|c|c|c|c|}
\hline & $\begin{array}{l}\text { Non-staging } \\
\text { surgery }\end{array}$ & Staging surgery & $\boldsymbol{P}$ Value \\
\hline Total & 330 & 118 & \\
\hline Age $(y$, mean \pm Std $)$ & $36.75 \pm 14.35$ & $38.03 \pm 12.49$ & 0.363 \\
\hline Time of operation(h, mean) & 127.50 & 255.00 & $<0.001$ \\
\hline Blood Loss (ml, median) & 80 & 400 & $<0.001$ \\
\hline Length of stay ( $d$, median) & 6 & 8 & $<0.001$ \\
\hline \multicolumn{4}{|l|}{ FIGO Stage } \\
\hline । & 287 (87\%) & $60(50.8 \%)$ & $<0.001$ \\
\hline$\|$ & $8(2.40 \%)$ & $12(10.2 \%)$ & \\
\hline III & $32(9.7 \%)$ & $42(35.6 \%)$ & \\
\hline IV & $3(0.9 \%)$ & $4(3.4 \%)$ & \\
\hline Histology & & & 0.038 \\
\hline Serous & $177(53.6 \%)$ & $81(68.6 \%)$ & \\
\hline Mucinous & $119(36.1 \%)$ & $31(26.3 \%)$ & \\
\hline Endometrioid & $7(2.1 \%)$ & $1(0.8 \%)$ & \\
\hline Serous and Mucinous & $27(8.2 \%)$ & $5(4.2 \%)$ & \\
\hline Lesion lateral & & & $<0.001$ \\
\hline Unilateral & $277(83.9 \%)$ & 75 (63.6\%) & \\
\hline Bilateral & $53(16.1 \%)$ & $43(36.4 \%)$ & \\
\hline \multicolumn{4}{|l|}{ Micropapillary } \\
\hline Yes & 45 (13.6\%) & $36(30.5 \%)$ & $<0.001$ \\
\hline No & $285(86.4 \%)$ & $82(69.5 \%)$ & \\
\hline Microinvasion & & & $<0.001$ \\
\hline Yes & $31(9.4 \%)$ & $57(48.3 \%)$ & \\
\hline No & $299(90.6 \%)$ & $61(51.7 \%)$ & \\
\hline \multicolumn{4}{|l|}{ Carcinogenesis } \\
\hline Yes & $14(4.2 \%)$ & $11(9.3 \%)$ & 0.058 \\
\hline No & $316(95.8 \%)$ & $107(90.7 \%)$ & \\
\hline Surgical Approach & & & $<0.001$ \\
\hline Laparotomy & $192(58.2 \%)$ & $106(89.8 \%)$ & \\
\hline Laparoscopy & $138(41.8 \%)$ & $12(10.2 \%)$ & \\
\hline Ascites/Cytologic washings & & & 0.012 \\
\hline Positive & $14(4.2 \%)$ & $13(11.0 \%)$ & \\
\hline Negative & $316(95.8 \%)$ & $105(89.0 \%)$ & \\
\hline Lymph node involvement & & & NA \\
\hline Yes & NA & $21(18.6 \%)$ & \\
\hline No & NA & $92(81.4 \%)$ & \\
\hline \multicolumn{4}{|l|}{ Appendix metastasis } \\
\hline Yes & $6(54.5 \%)$ & $5(45.5 \%)$ & 0.05 \\
\hline No & $113(81.3 \%)$ & $26(18.7 \%)$ & \\
\hline Omentum metastasis & & & NA \\
\hline Yes & NA & $27(23.1 \%)$ & \\
\hline No & NA & $90(76.9 \%)$ & \\
\hline Adjuvant chemotherapy & & & $<0.001$ \\
\hline
\end{tabular}

Table 1 Demographics of patients with borderline ovarian tumors (Continued)

\begin{tabular}{llll}
\hline & $\begin{array}{l}\text { Non-staging } \\
\text { surgery }\end{array}$ & Staging surgery & $\boldsymbol{P}$ Value \\
\hline Yes & $54(16.4 \%)$ & $67(56.8 \%)$ & \\
No & $276(83.6 \%)$ & $51(43.2 \%)$ & \\
Recurrence & & & 0.007 \\
Yes & $30(9.1 \%)$ & $22(18.6 \%)$ & \\
No & $300(90.9 \%)$ & $96(81.4 \%)$ & $<0.001$ \\
Fertility-sparing surgery & & & \\
Yes & $240(72.7 \%)$ & $30(25.4 \%)$ & 0.552 \\
No & $90(27.3 \%)$ & $88(74.6 \%)$ & \\
Achieving pregnancy & & & \\
Yes & $79(35.7 \%)$ & $13(41.9 \%)$ & \\
No & $142(64.3 \%)$ & $18(58.1 \%)$ & \\
\hline
\end{tabular}

Data were recorded as number (\%), mean $( \pm \mathrm{SD})$, or median (range) Abbreviations: y Years, $h$ Hours, $d$ Days

patients (6.03\%). Lymph node metastasis was detected in 21 of 113 patients (18.58\%) who underwent lymphadenectomy. Appendix metastases were detected in 11 of 150 patients (7.33\%) who underwent appendectomy. Omentum metastases were detected in 27 of 117 patients $(23.08 \%)$ who underwent omentectomy. A total of 121 patients (27.01\%) received adjuvant chemotherapy for lymph node metastasis, positive abdominal/pelvic washings, invasive implants, and/or other high-risk indicators.

\section{Oncological outcomes of BOT patients}

We carried out a survival analysis. The median followup for this study was 113 (range: 14-166) months. At the last follow-up, 42 (11.6\%) patients experienced recurrence, with a mean recurrence interval of 80.2 months, and $4(0.9 \%)$ disease-specific deaths were observed. The recurrence rate in patients who underwent non-staging surgery $(30 / 330,9.09 \%)$ was lower than that in those underwent staging surgery $(22 / 118,18.64 \%)$, with the difference being statistically significant $(P<$ 0.01 ). The results of univariate and multivariate analyses of DFS in all patients are shown in Table 2.

According to the univariate analysis, patients who underwent staging surgery had shorter DFS than those who underwent non-staging surgery. In addition, laparoscopy was strongly associated with improved DFS (HR $=0.292,95 \%$ CI: $0.132-0.647, P=$ 0.002) compared to laparotomy. Other factors found to be associated with DFS were FIGO stage, histology, lesion location, microinvasion, adjuvant chemotherapy, ascites/pelvic washings, cancer antigen (CA)-125 level, appendectomy, and invasive implants (all $P<0.01$ ). Micropapillary and carcinogenic lesions were not associated with DFS $(P>0.05)$. 
Table 2 Univariate and multivariate analysis of DFS

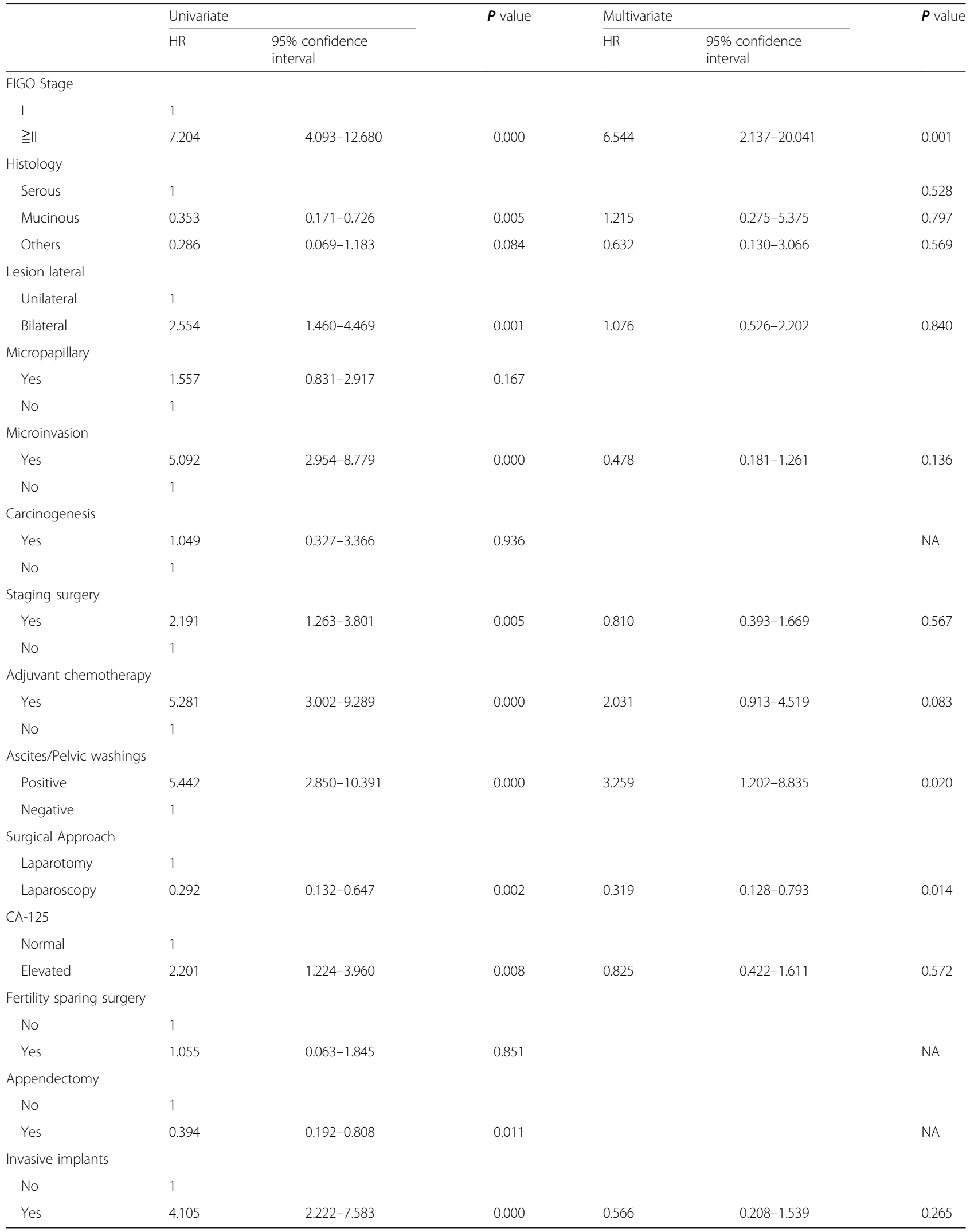


Although several factors were found to be associated with DFS by univariate analysis, only FIGO stage (OR: $6.544,95 \%$ CI: $2.137-20.041)$, positive ascites/pelvic washings (OR: $3.259,95 \% \mathrm{CI}: 1.202-8.835$ ), and surgical approach (OR: 0.319, 95\% CI: 0.128-0.793) were significantly associated with DFS $(P<0.001, P=0.014, P=$ 0.043 , respectively) as per multivariate analysis; complete staging surgery was not associated with DFS $(P=0.600)$ as per multivariate analysis. There was no difference in DFS between patients who underwent FSS and radical surgery according to univariate and multivariate analyses.

Subgroup analysis showed that in patients who underwent staging surgery, there was no difference in DFS between those who underwent laparotomy or laparoscopy $(P=0.349)$. Among patients who underwent non-staging surgery, the DFS was longer for patients who underwent laparoscopy than for those who underwent laparotomy $(P=0.011$; Supplementary Table 1$)$.

\section{Oncological outcomes in patients with BOT after FSS}

Among the patients enrolled, 270 patients underwent FSS. Of these, 32 patients (11.8\%) experienced recurrence. To explore the potential risk factors associated with improved DFS in patients who underwent FSS, univariate and multivariate analyses were performed (Table 3).

Univariate analysis with patients who underwent FSS showed that patients who underwent staging surgery had shorter DFS than those who underwent non-staging procedures (OR: 4.290, 95\% CI: 1.9799.298, $P<0.001)$. DFS was better among patients who underwent laparoscopy (OR: 0.332, 95\% CI: 0.135$0.820, P=0.017)$ than among those who underwent laparotomy. In addition, patients who underwent salpingo-oophorectomy had longer DFS than those who underwent a cystectomy procedure (OR: 0.230, 95\% CI: $0.168-0.867, P=0.021)$. Other factors were also associated with DFS in patients who underwent FSS, including FIGO stage, histology, lesion location, microinvasion, adjuvant chemotherapy, positive ascites/pelvic washings, appendectomy, and invasive implants $(P<0.05)$.

In multivariate analysis, there was no difference in DFS between patients who underwent staging and non-staging surgery $(P=0.358)$. There was no difference in DFS between patients with different histological types. Early FIGO stage (OR: 11.586, 95\% CI: 4.535-29.602), unilateral lesions (OR: 2.581, 95\% CI: 1.061-6.283), laparoscopy (OR: 0.367, 95\% CI: $0.148-$ 0.913), salpingo-oophorectomy (OR: 0.367, 95\% CI: 0.148-0.913), and no invasive implants (OR: 4.832, 95\% CI: $1.663-14.037)$ were independent factors for improved DFS $(P<0.05)$.

\section{Reproductive outcomes in patients with BOT after FFS}

At the last follow-up, of the 270 patients who underwent FSS, 252 patients had attempted to conceive and 92 achieved pregnancy. The correlation between clinicopathological characteristics and reproductive outcome is shown in Table 4. The pregnancy rate in patients aged $<35$ years was higher than those aged $\geqq 35$, at a statistically significant $(P<0.001)$ level. Of the 30 patients who underwent staging surgery, 13 patients $(43.33 \%)$ succeeded in conceiving, whereas 79 of 203 patients (38.92\%) who underwent non-staging surgery succeeded in conceiving, but these differences were not statistically significant $(P>0.05)$. There was no difference between patients who underwent laparotomy or laparoscopy. Similarly, among patients who underwent salpingooophorectomy or cystectomy, there was no difference in the pregnancy rates $(P>0.05)$.

\section{Discussion}

In the present study, we performed a retrospective analysis of 448 patients with BOT in a single centre in China. BOTs are ovarian neoplasms with characteristics of benign or malignant tumours, frequently occurring in young women and associated with favourable prognosis. Within the past two decades, we have begun to understand the biological behaviour of BOTs; however, the optimal therapy for this disease is still controversial. Numerous studies have focused on the oncological and reproductive outcomes of $\mathrm{BOT}$. In the literature, the primary points of discussion regarding BOT include the prognostic factors for overall survival (OS) or DFS, necessity of staging surgery, application of minimally invasive approaches, and outcome of conservative surgery.

Complete staging surgery generally includes resection of the primary borderline tumour (cystectomy or salpingo-oophorectomy), cytologic washings, omentectomy, peritoneal biopsies, and routine lymphadenectomy. Unlike in ovarian cancer, previous studies have shown that the prognosis of patients with BOT is generally favourable, with very low mortality $[13,14]$. A Turkish Gynaecologic Oncology Group (GOG) study showed that the five-year survival rate of patients with BOT was $100 \%$, and the median survival time was 120 months [15]. Therefore, DFS and recurrence-free survival (RFS) were defined as the main oncological outcomes. In the present study, complete staging surgery was performed in $26.3 \%$ of the patients. Although univariate analysis showed that patients who underwent staging surgery had shorter DFS than those who underwent non-staging surgery, no significant difference was found in the DFS between different surgical approaches as per multivariate analysis. These results were similar to those of previous studies [2, 12, 15-17]. The Turkish GOG study showed that comprehensive surgical staging did not lead to any 
Table 3 Univariate and multivariate analysis of DFS in fertility desiring patients after fertility-sparing surgery

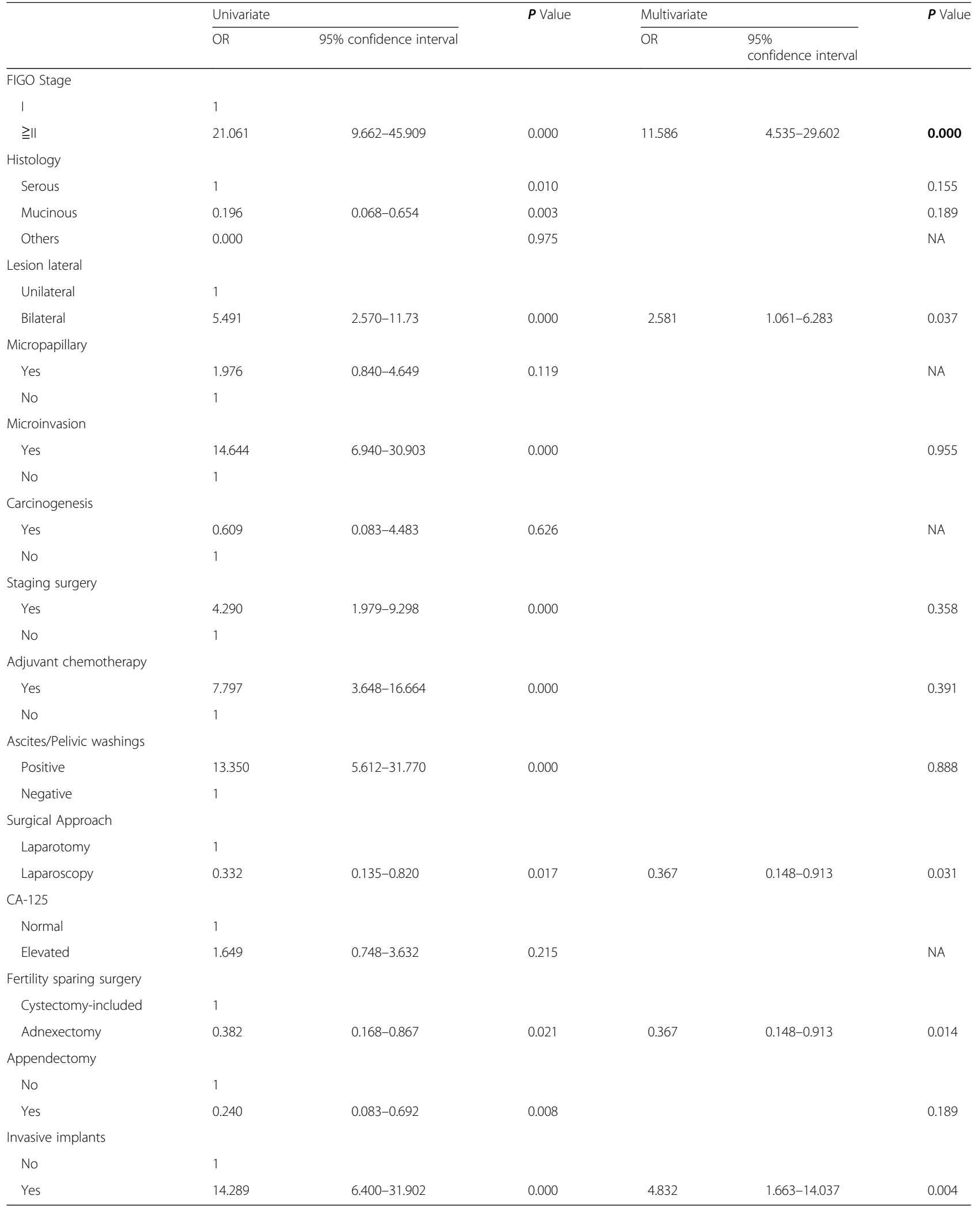


Table 4 Correlation between pregnant outcomes and clinicopathological indexes in patients after fertility-sparing surgery

\begin{tabular}{|c|c|c|c|}
\hline & \multicolumn{2}{|c|}{ Fertility outcome } & \multirow[t]{2}{*}{$\boldsymbol{P}$ value } \\
\hline & $\begin{array}{l}\text { No } \\
(n, \%)\end{array}$ & $\begin{array}{l}\text { Yes } \\
(n, \%)\end{array}$ & \\
\hline \multicolumn{4}{|l|}{ Staging surgery } \\
\hline No & $124(87.9)$ & $79(85.9)$ & \multirow[t]{2}{*}{0.691} \\
\hline Yes & $17(12.1)$ & $13(14.1)$ & \\
\hline \multicolumn{4}{|l|}{ Surgical approach } \\
\hline Laparoscopy & $65(46.1)$ & $37(40.2)$ & \multirow[t]{2}{*}{0.419} \\
\hline Laparotomy & $76(53.9)$ & $55(59.8)$ & \\
\hline \multicolumn{4}{|l|}{ Surgical procedure } \\
\hline Cystectomy & $76(53.9)$ & $41(44.6)$ & \multirow[t]{2}{*}{0.181} \\
\hline Salpingo-oophorectomy & $65(46.1)$ & $51(55.4)$ & \\
\hline \multicolumn{4}{|l|}{ Adjuvant chemotherapy } \\
\hline No & $110(78.0)$ & $77(83.7)$ & \multirow[t]{2}{*}{0.316} \\
\hline Yes & $31(22.0)$ & $15(16.3)$ & \\
\hline \multicolumn{4}{|l|}{ FIGO Stage } \\
\hline । & $121(85.8)$ & $84(91.3)$ & \multirow[t]{2}{*}{0.225} \\
\hline$\geqq \|$ & $20(14.2)$ & $8(8.7)$ & \\
\hline \multicolumn{4}{|l|}{ Histology } \\
\hline Serous & 79 (56.0) & $39(42.4)$ & \multirow[t]{3}{*}{0.08} \\
\hline Mucinous & $47(33.3)$ & $44(47.8)$ & \\
\hline Others & $15(10.6)$ & $9(9.8)$ & \\
\hline \multicolumn{4}{|l|}{ Lesion lateral } \\
\hline Unilateral & $122(86.5)$ & $82(89.1)$ & \multirow[t]{2}{*}{0.686} \\
\hline Bilateral & $19(13.5)$ & $10(10.9)$ & \\
\hline \multicolumn{4}{|l|}{ Micropapillary } \\
\hline No & $23(16.3)$ & $12(13.0)$ & \multirow[t]{2}{*}{0.576} \\
\hline Yes & $118(83.7)$ & $80(87.0)$ & \\
\hline \multicolumn{4}{|l|}{ Microinvasion } \\
\hline No & $126(89.4)$ & $85(92.4)$ & \multirow[t]{2}{*}{0.499} \\
\hline Yes & $15(10.6)$ & $7(7.6)$ & \\
\hline \multicolumn{4}{|l|}{ Carcinogenesis } \\
\hline No & $134(95.0)$ & $86(93.5)$ & \multirow[t]{2}{*}{0.771} \\
\hline Yes & $7(5.0)$ & $6(6.5)$ & \\
\hline \multicolumn{4}{|l|}{ Ascites/Pelvic washings } \\
\hline Positive & $7(5.0)$ & $3(3.3)$ & \multirow[t]{2}{*}{0.744} \\
\hline Negative & $134(95.0)$ & $89(96.7)$ & \\
\hline \multicolumn{4}{|l|}{ CA-125 } \\
\hline Normal & $82(65.6)$ & $60(69.8)$ & 0.553 \\
\hline Elevated & $43(34.4)$ & $26(30.2)$ & \\
\hline Invasive implants & & & \\
\hline No & $132(93.6)$ & $88(95.7)$ & 0.574 \\
\hline Yes & $9(6.4)$ & $4(4.3)$ & \\
\hline Age & & & \\
\hline$<35$ & $107(75.9)$ & $92(100)$ & 0.000 \\
\hline$\geqq 35$ & $34(24.1)$ & 0 & \\
\hline
\end{tabular}


difference in survival [15]. A retrospective multicentre study showed that there were no differences in the fiveyear RFS and OS between patients who did and did not undergo complete surgical staging [18]. Another multicentre study showed that surgical staging were not beneficial in the management of BOT [12]. A third multicentre study from Turkey that focused on mucinous BOT showed that radical surgery, omentectomy, appendectomy, and lymphadenectomy were not independent prognostic factors for progression-free survival and OS [17].

Regarding the correlation between lymphadenectomy and DFS, lymph node involvement does not appear to be a prognostic factor $[19,20]$. Univariate analysis by Matsuo et al. showed that surgical staging patterns for hysterectomy and lymphadenectomy were not associated with cause-specific survival $(P=0.19)$ [2]. A previous study by Qian et al. showed that there were no significant differences between groups with or without lymphatic node involvement $(P=0.778)$, and between patients who had more or fewer than 10 nodes removed $(P=0.549)$ [16].

BOT occurs in women of all ages, with a high proportion in the reproductive age [21]. In the present study, the median age at diagnosis was 37.1 years. Therefore, a conservative surgical approach (FSS) was the preferred choice for patients who desired to preserve their fertility. However, the balance between oncological and reproductive outcomes should be assessed adequately; approximately $12-36 \%$ of the patients with BOT who undergo FSS experience recurrence [21], and the most common site of recurrence is the residual ovary [21-24]. Previous studies have shown that the recurrence rate of BOT in patients who underwent FSS was markedly higher than that in patients who underwent radical surgeries $(21.4 \%$ vs. $6.3 \%, P<0.05)[10,25]$. Furthermore, a large proportion of patients who underwent FSS experienced invasive recurrence [14]. In a recent retrospective study, patients with FSS developed more relapse than patients with radical surgeries [26]. In the multivariate analyses, fertility preservation and micropapillary pattern were independently associated with adverse disease-free survival $(P=0.001,0.03$ and 0.026 , respectively) [26]. Regarding surgical patterns, a meta-analysis showed that unilateral cystectomy is significantly associated with high recurrence rates [11]. However, another study reported that there was no statistically significant difference between patients who underwent cystectomy or unilateral salpingo-oophorectomy [27]. A recent study involving 6295 patients showed that FSS was associated with worse DFS in patients aged $\geq 50$ years than in those aged $<50$ years [28]. Another study showed that surgical procedure (conservative vs. radical) was not an independent prognostic factor for DFS or OS [12].
In the present study, both univariate and multivariate analyses results showed no significant difference in the DFS between patients who underwent FSS and those who did not $(P>0.05)$. In patients who underwent FSS, there was no significant difference in DFS between those who underwent staging and those who did not $(P>0.05)$, whereas a significant difference was observed between those who underwent laparoscopy and laparotomy $(P<0.05)$. However, no significant differences were found in the reproductive rates of those who underwent staging surgery or a different surgical approach. Therefore, the balance between oncological and reproductive outcomes in patients of reproductive age should be considered before performing FSS.

The standard treatment for BOT is surgery. Since most patients are of childbearing age, surgeons should consider using a minimally invasive procedure. Laparoscopic surgery has several advantages over open surgery in the management of gynaecologic diseases, including fewer peri-operative complications and superior cosmetic outcomes. In this study, approximately $33.48 \%$ of the patients underwent laparoscopic surgery. As per both univariate and multivariate analyses findings, laparoscopic surgery was more positively associated with improved DFS than laparotomy $(P<0.05)$. Similarly, a previous study by Song et al. also showed that RFS and OS did not differ between the laparoscopy (single-port and multi-port laparoscopy) and laparotomy groups [29]. However, the potential selective bias should be noticed, which means that the characteristic of individual patients might influence the surgery approach. For those patients with smaller mass, younger ages, lower CA125 levels in pre-operative time, laparoscopy may be more favorable, usually getting a better prognosis. However, for those patients with larger mass, older ages, higher CA125 levels, or other signs suspected for malignant tumors in pre-operative time, laparotomy was possibly chosen. This bias could be solved through increasing patients enrolled, or randomized controlled trial.

In a retrospective study of 1069 patients with BOT in Japan, 49\% had normal serum CA-125 levels and only $23 \%$ had serum CA-125 levels above $100 \mathrm{U} / \mathrm{mL}$ [21]. In another study of 198 patients in Singapore, the preoperative serum CA-125 levels of 77 (39\%) patients were $>35 \mathrm{U} / \mathrm{mL}$ [30]. In the present study, the serum level of CA-125 was not an independent prognostic factor for patients with BOT after FSS.

Because an accurate intra-operative diagnosis is important in the management of BOT, frozen-section examination should be performed to help surgeons and patients' families make decisions during intra-operative periods. The accuracy of frozen-section examination is lower than optimal and the availability of reliable frozensection analysis methods in many hospitals is difficult. 
Previous studies have shown that the matched rate between the results of frozen-section and definitive histological examination varies from 66.67 to $88.9 \%$ [31, 32]. Therefore, it is important for surgeons to counsel patients and their families with regard to possible intraoperative indications.

\section{Conclusions}

Patients with BOT do not benefit from surgical staging procedures in terms of prognosis and fertility outcomes. Laparoscopy, rather than laparotomy, should be recommended for patients with stage I disease who wish to preserve their fertility. In addition, patients with advanced stage disease, invasive implants, and/or bilateral tumours who wish to maintain their fertility should consider the risk of recurrence before choosing FSS. Unilateral salpingo-oophorectomy is an alternative method for patients with BOT to preserve their fertility.

\section{Supplementary information}

Supplementary information accompanies this paper at https://doi.org/10. 1186/s12885-020-07262-w.

Additional file 1: Table S1. Subgroup analysis of staging surgery in DFS of patients undergoing laparoscopy or laparotomy.

\section{Abbreviations}

BOT: Borderline ovarian tumour; DFS: Disease-free survival; FIGO: Federation of Gynecology and Obstetrics; FSS: Fertility-sparing surgery; GOG: Gynaecologic Oncology Group; HR: Hazard ratios; OS: Overall survival; RFS: Recurrence-free survival; SPSS: Statistical Package for Social Sciences; WHO: World Health Organization

\section{Acknowledgements}

The authors would like to thank all pathologists in department of Pathology (West China Second University Hospital, Sichuan University, China) for the pathological diagnosis of BOT.

\section{Authors' contributions}

$\mathrm{NL}$, JG were involved in all research activities, data collection, data analysis, development of study document and manuscript drafting. $L L, X M, T H$ contributed to collection of clinical data and data analysis. ZL made the study design. All authors have read and approved the manuscript.

\section{Funding}

Not applicable.

\section{Availability of data and materials}

The datasets used and analysed during the current study available from the corresponding author on reasonable request.

\section{Ethics approval and consent to participate}

The study was approved by the Medical Ethics Committee of West China Second University Hospital, Sichuan University. Due to the nature of retrospective study, no written informed consent was obtained from patients. All follow-up information were approved by telephone review or out-patient review.

\section{Consent for publication}

Not applicable.

\section{Competing interests}

The authors have no competing interests to declare.

\section{Author details}

'Department of Gynecology and Obstetrics, West China Second University Hospital, Sichuan University, Chengdu, Sichuan 610041, P.R. China. ${ }^{2}$ Key Laboratory of Obstetrics \& Gynecologic and Pediatric Diseases and Birth Defects of Ministry of Education, West China Second Hospital, Sichuan University, Chengdu, Sichuan 610041, P.R. China. ${ }^{3}$ Department of Obstetrics and Gynecology, The First Affiliated Hospital of Zunyi Medical University, Zunyi, Guizhou 563000, P.R. China.

Received: 18 February 2020 Accepted: 5 August 2020

Published online: 17 August 2020

\section{References}

1. Fischerova D, Zikan M, Dundr P, Cibula D. Diagnosis, treatment, and followup of borderline ovarian tumors. Oncologist. 2012;17:1515-33.

2. Matsuo K, Machida H, Takiuchi T, Grubbs BH, Roman LD, Sood AK, et al. Role of hysterectomy and lymphadenectomy in the management of early-stage borderline ovarian tumors. Gynecol Oncol. 2017;144:496-502.

3. Guadagno E, Pignatiello S, Borrelli G, Cervasio M, Della L, Bifulco G, et al. Ovarian orderline tumors, a subtype of neoplasm with controversial behavior. Role of Ki67 as a prognostic factor. Pathol Res Pract. 2019;215: 152633.

4. Gershenson DM, Silva EG, Tortolero-Luna G, Levenback C, Morris M, Tornos C. Serous borderline tumors of the ovary with noninvasive peritoneal implants. Cancer. 1998:83:2157-63.

5. Fotopoulou C, Schumacher G, Schefold JC, Denkert C, Lichtenegger W, Sehouli J. Systematic evaluation of the intraoperative tumor pattern in patients with borderline tumor of the ovary. Int J Gynecol Cancer. 2009;19: 1550-5

6. Menczer J, Chetrit A, Sadetzki S, National Israel Ovarian Cancer G. The effect of hysterectomy on survival of patients with borderline ovarian tumors. Gynecol Oncol. 2012;125:372-5.

7. Shazly SA, Laughlin-Tommaso SK, Dowdy SC, Famuyide AO. Staging for low malignant potential ovarian tumors: a global perspective. Am J Obstet Gynecol. 2016;215(2):153-68..e152.

8. Messalli EM, Grauso F, Balbi G, Napolitano A, Seguino E, Torella M. Borderline ovarian tumors: features and controversial aspects. Eur J Obstet Gynecol Reprod Biol. 2013;167:86-9.

9. Petru E, Luck HJ, Stuart G, Gaffney D, Millan D, Vergote I, et al. Gynecologic Cancer Intergroup (GCIG) proposals for changes of the current FIGO staging system. Eur J Obstet Gynecol Reprod Biol. 2009;143:69-74.

10. Fang C, Zhao L, Chen X, Yu A, Xia L, Zhang P. The impact of clinicopathologic and surgical factors on relapse and pregnancy in young patients $(</=40$ years old) with borderline ovarian tumors. BMC Cancer. 2018:18:1147.

11. Jiao $\mathrm{X}, \mathrm{Hu}$ J, Zhu L. Prognostic factors for recurrence after fertility-preserving surgery in patients with borderline ovarian tumors: a systematic review and meta-analysis of observational studies. Int J Gynecol Cancer. 2017;27:183341.

12. Gokcu M, Gungorduk K, Asicioglu O, Cetinkaya N, Gungor T, Pakay G, et al. Borderline ovarian tumors: clinical characteristics, management, and outcomes - a multicenter study. J Ovarian Res. 2016;9:66.

13. Lou T, Yuan F, Feng Y, Wang S, Bai H, Zhang Z. The safety of fertility and ipsilateral ovary procedures for borderline ovarian tumors. Oncotarget. 2017; 8:115718-29.

14. Zanetta G, Rota S, Chiari S, Bonazzi C, Bratina G, Mangioni C. Behavior of borderline tumors with particular interest to persistence, recurrence, and progression to invasive carcinoma: a prospective study. J Clin Oncol. 2001; 19:2658-64.

15. Guvenal T, Dursun P, Hasdemir PS, Hanhan M, Guven S, Yetimalar H, et al. Effect of surgical staging on 539 patients with borderline ovarian tumors: a Turkish gynecologic oncology group study. Gynecol Oncol. 2013;131:54650.

16. Qian $X Q$, Hua XP, Wu JH, Shen YM, Cheng XD, Wan XY. Clinical predictors of recurrence and prognostic value of lymph node involvement in the serous borderline ovarian tumor. Int J Gynecol Cancer. 2018;28:279-84.

17. Gungorduk K, Asicioglu O, Braicu El, Almuheimid J, Gokulu SG, Cetinkaya N, et al. The impact of surgical staging on the prognosis of mucinous borderline tumors of the ovaries: a multicenter study. Anticancer Res. 2017; 37:5609-16 
18. Bendifallah S, Nikpayam M, Ballester M, Uzan C, Fauvet R, Morice P, et al. New pointers for surgical staging of borderline ovarian tumors. Ann Surg Oncol. 2016;23:443-9.

19. Longacre TA, McKenney JK, Tazelaar HD, Kempson RL, Hendrickson MR. Ovarian serous tumors of low malignant potential (borderline tumors): outcome-based study of 276 patients with long-term ( $>$ or $=5$-year) followup. Am J Surg Pathol. 2005;29:707-23.

20. Lesieur B, Kane A, Duvillard P, Gouy S, Pautier P, Lhomme C, et al. Prognostic value of lymph node involvement in ovarian serous borderline tumors. Am J Obstet Gynecol. 2011;204:438.e431-7.

21. Gershenson DM. Management of borderline ovarian tumours. Best Pract Res Clin Obstet Gynecol. 2017;41:49-59.

22. Yinon Y, Beiner ME, Gotlieb WH, Korach Y, Perri T, Ben-Baruch G. Clinical outcome of cystectomy compared with unilateral salpingo-oophorectomy as fertility-sparing treatment of borderline ovarian tumors. Fertil Steril. 2007; 88:479-84.

23. Park JY, Kim DY, Kim JH, Kim YM, Kim YT, Nam JH. Surgical management of borderline ovarian tumors: the role of fertility-sparing surgery. Gynecol Oncol. 2009;113:75-82.

24. Song T, Choi CH, Park HS, Kim MK, Lee YY, Kim TJ, et al. Fertility-sparing surgery for borderline ovarian tumors: oncologic safety and reproductive outcomes. Int J Gynecol Cancer. 2011;21:640-6.

25. Sun L, Li N, Song Y, Wang G, Zhao Z, Wu L. Clinicopathologic features and risk factors for recurrence of mucinous borderline ovarian tumors: a retrospective study with follow-up of more than 10 years. Int J Gynecol Cancer. 2018;28:1643-9.

26. Jia Z, Xiang Y, Yang J, Shi H, Jia W, Leng H. Oncofertility outcomes after fertility-sparing treatment of bilateral serous borderline ovarian tumors: results of a large retrospective study. Hum Reprod. 2020;35:328-39.

27. Song T, Hun Choi C, Lee YY, Kim TJ, Lee JW, Bae DS, et al. Oncologic and reproductive outcomes of cystectomy compared with oophorectomy as a treatment for borderline ovarian tumours. Hum Reprod. 2011;26:2008-14.

28. Sun $\mathrm{H}$, Chen X, Zhu T, Liu N, Yu A, Wang S. Age-dependent difference in impact of fertility preserving surgery on disease-specific survival in women with stage | borderline ovarian tumors. J Ovarian Res. 2018:11:54

29. Song T, Kim MK, Jung YW, Yun BS, Seong SJ, Choi CH, et al. Minimally invasive compared with open surgery in patients with borderline ovarian tumors. Gynecol Oncol. 2017;145:508-12.

30. Wong HF, Low JJ, Chua Y, Busmanis I, Tay EH, Ho TH. Ovarian tumors of borderline malignancy: a review of 247 patients from 1991 to 2004. Int J Gynecol Cancer. 2007;17:342-9.

31. Yoshida A, Tavares BVG, Sarian LO, Andrade L, Derchain SF. Clinical features and management of women with borderline ovarian tumors in a single center in Brazil. Rev Bras Ginecol Obstet. 2019:41:176-82.

32. Koensgen D, Weiss M, Assmann K, Brucker SY, Wallwiener D, Stope MB, et al. Characterization and management of borderline ovarian tumors results of a retrospective, single-center study of patients treated at the Department of Gynecology and Obstetrics of the University Medicine Greifswald. Anticancer Res. 2018;38:1539-45.

\section{Publisher's Note}

Springer Nature remains neutral with regard to jurisdictional claims in published maps and institutional affiliations.

Ready to submit your research? Choose BMC and benefit from:

- fast, convenient online submission

- thorough peer review by experienced researchers in your field

- rapid publication on acceptance

- support for research data, including large and complex data types

- gold Open Access which fosters wider collaboration and increased citations

- maximum visibility for your research: over $100 \mathrm{M}$ website views per year

At BMC, research is always in progress.

Learn more biomedcentral.com/submissions 